\title{
Protective effect of propolis on manganese chloride neurotoxicity of olfactory bulb in adult male albino rat
}

\author{
O.M. Mahmoud', N.A. Salem¹, M.H. Al Badawi \\ ${ }^{1}$ Department of Human Anatomy and Embryology, Faculty of Medicine, Suez Canal University, Ismailia, Egypt \\ 2Department of Human Anatomy and Embryology, Faculty of Medicine, Helwan University, Cairo, Egypt
}

[Received: 9 September 2020; Accepted: 17 November 2019]

Background: Manganese (Mn) is widely used for industrial purposes and exposure to high levels of Mn may cause an irreversible brain disease. Propolis is a natural plant product; it acts as a powerful reactive oxygen species scavenger and improves the neurodegeneration process.

Materials and methods: In this study 40 adult male albino rats were divided randomly into four groups 10 rats each: group I (control group), group II manganese chloride (MnCl2) received $10 \mathrm{mg} / \mathrm{kg} /$ day/orally for 4 weeks by intra-gastric tube, group III (propolis group) received $50 \mathrm{mg} / \mathrm{kg} /$ day/orally for 4 weeks by intra-gastric tube, and group IV (MnCl2 + propolis group) received the same doses with the same duration and route as in groups II and III. Rats were sacrificed after $24 \mathrm{~h}$ of last dose. The olfactory bulbs removed, the right bulb cut to be processed for haematoxylin and eosin, immunohistochemical staining and the left cut for electron microscopic studies.

Results: Results revealed that rat olfactory bulb from MnCl2 group showed darkly stained mitral cells with dark pyknotic nuclei, some show pericellular spaces and vacuolation, dark apoptotic cells in granular cells, neuropil vacuolation and pyknotic astrocyte. Electron microscopic examination showed abnormal granular cell with irregular damaged nuclear membrane, rupture of myelin fibre. Mitral nerve cell with destructed nucleus, many cytoplasmic vacuoles, swollen rough endoplasmic reticulum, vacuolated mitochondria and neuropil were observed. Manganese chloride + propolis group showed improvement compared to $\mathrm{MnCl} 2$ group.

Conclusions: It was concluded that propolis can ameliorate the toxic changes of manganese chloride on rat olfactory bulb. (Folia Morphol 2020; 79, 4: 672-680)

Key words: olfactory bulb, manganese chloride, propolis, rat

\section{INTRODUCTION}

Odour impairment is associated with preclinical dementia in humans, so it is essential to develop experimental models to evaluate the effects of neuropathology on behaviour. The sense of olfaction is critically important for food consumption, maternal reproductive functions, emotional responses and neu- roendocrine regulation. In many species, olfaction plays a very important role in animals' functions than in humans [16].

Manganese $(\mathrm{Mn})$ is widely used for manufacture purposes, including the production of steel, iron, fertilizers, ceramics, batteries, insecticides, paints, and soaps [7]. Metal and mine workers are frequently

Address for correspondence: Dr. O.M. Mahmoud, Department of Human Anatomy and Embryology, Faculty of Medicine, Suez Canal University, Postal code: 41111, Ismailia, Egypt, tel: 01272759000, e-mail: omima34@hotmail.com 
exposed to $\mathrm{Mn}$ [24]. It is an essential metal for humans, which disturbs the controlled balance of neurotransmitters release and metabolism. Therefore $\mathrm{Mn}$ haemostasis is necessary for all brain function [10]. It acts as an activator or cofactor for many metalloenzymes, as mitochondrial superoxide-dismutase that is an avital enzyme in the suppression of oxidative stress [39]. Manganese passed the blood-brain barrier and carried to various brain parts through an axonal transport system [42]. It was stated that exposure to Mn high levels leads to permanent brain disease [45].

Propolis is a resinous substance produced by honeybees from plants. It is composed of resin $(50 \%)$, wax $(30 \%)$, pollen $(5 \%)$ and aromatic oils $(10 \%)$, flavonoids (quercetin, chrysin, pinocembrin, kaempferol, apigenin, etc.), polyphenolics, beta-steroids, terpenes, vitamins, and minerals. It has relevant therapeutic properties that have been used since ancient times [6]. Its flavonoid component, caffeic acid phenethyl ester, possesses several important biological and pharmacological properties including immunomodulatory, antioxidant, anti-inflammatory, anticarcinogenic, antiviral, antimicrobial, neuroprotective effect and anti-diabetic activities [38].

Propolis acts as a potent reactive oxygen species (ROS) scavenger. It improves the neurodegeneration process after sciatic nerve injury [37]. Also, it greatly improved the level of acetylcholinesterase activity, oxidative stress, and mitochondrial dysfunction in lead-induced neurotoxicity [15].

Earlier identification of neurodegenerative diseases is a major objective. In preclinical studies testing new neuroprotective approaches in rodent models of neurodegenerative disease, olfactory assessment could be very useful in determining therapeutic potential of compounds and transfer into clinic [27]. So, this study aims to evaluate the protective effect of propolis against manganese chloride $(\mathrm{MnCl} 2)$ neurotoxicity on the olfactory bulb of adult albino rate.

\section{MATERIALS AND METHODS}

\section{Chemicals}

Manganese chloride $97 \%$ (tetrahydrate) was purchased from ALPHA CHEMIKA, India.

\section{Preparation of aqueous propolis extract}

Propolis was obtained from honeybee colonies at the apiary of the Faculty of Agriculture at Suez Canal University, Egypt. Propolis freeze until usage, samples were mixed with distilled water, heated and filtered through filter paper. It was freshly prepared to be sure that it contains all its active components given orally by intragastric tube daily at a dose of $50 \mathrm{mg} / \mathrm{kg} /$ day for 4 weeks [15]. Oral administration of propolis is safe up to $5000 \mathrm{mg} / \mathrm{kg} /$ day [32].

\section{Animals}

Forty adult male Sprague Dawley albino rats weighing between 150 and $200 \mathrm{~g}$ purchased from Faculty Veterinary Medicine, Suez Canal University. They kept in a ventilated room in stainless-steel cages at Human Anatomy and Embryology Department, Faculty of Medicine, Suez Canal University. They were left 2 weeks to accommodate, received food and water ad libitum. The animals were weighted daily and observed for behavioural changes.

\section{Experimental design}

Forty adult male albino rats randomly divided into four groups ten rats each:

- group I (control group) divided into two subgroups: negative control: no treatment was received, and positive control received $0.5 \mathrm{~mL}$ distilled water daily by intra-gastric tube for 4 weeks;

- group II ( $\mathrm{MnCl} 2)$ : rats received $10 \mathrm{mg} / \mathrm{kg} /$ day/orally for 4 weeks, which dissolved in $1 \mathrm{~mL}$ of sterile saline by intra-gastric tube [35];

- group III (propolis group): rats received $50 \mathrm{mg} / \mathrm{kg} /$ /day/orally for 4 weeks by intra-gastric tube [15];

- group IV ( $\mathrm{MnCl} 2$ + propolis group): rats received the same doses, duration, and route as groups II and III.

Rats sacrificed $24 \mathrm{~h}$ after the last dose, the olfactory bulbs were collected immediately, the right bulb cut to be processed for haematoxylin and eosin (H\&E), immunohistochemical staining and the left one cut for electron microscopic studies.

\section{Buried food test}

The test is used to confirm ability to smell volatile odour and measures how rapidly an overnight-fasted animal can find familiar food, such as hiding cookies underneath a layer of $3 \mathrm{~cm}$ clean bedding in a clean cage. Stopwatch and timer were used for each cage, rat with normal olfaction find the cookies within $1 \mathrm{~min}$. Stop the stopwatch when the rat picks up the cookies. Rat fails to find the cookies after 15 min we record $900 \mathrm{~s}$ as its latency score [43]. 


\section{Light microscopic study}

Right olfactory bulb was cut and fixed in $10 \%$ neutral buffered formalin and processed for light microscopic study. Paraffin sections of 5- $\mu \mathrm{m}$ thickness were stained with H\&E and immunohistochemically staining with glial fibrillary acidic protein (GFAP) of glial cells (purchased from Lab vision, USA) [33]. Area per cent of GFAP immunoreaction were measured using ImageJ soft $[1,36]$.

\section{Electron microscopic study}

The specimens of the left bulbs were divided into small pieces, immersed for $2 \mathrm{~h}$ in $2.5 \%$ phosphate-buffered glutaraldehyde solution $\left(\mathrm{pH} \mathrm{7.4)}\right.$ at $4^{\circ} \mathrm{C}$, washing with phosphate buffer then post-fixed for $1 \mathrm{~h}$ in $1 \%$ buffered osmium tetroxide solution. Ultrathin sections were cut using MT 600-XL RMC ultra-tome, stained with uranyl acetate and lead citrate and examined with JOEL-1010 (Japan) transmission electron microscope at the centre of Mycology and Biotechnology Transmitting Electron unit, Al-Azhar University, Cairo, Egypt.

\section{Ethical consideration}

All procedures performed in this study involving animals were done accordance the ethical standards of the Institutional Animals Ethics Committee of Suez Canal University.

\section{Statistical analysis}

The morphometric data of each group was statistically analysed; ANOVA and post-hoc Tukey's HSD were used to compare the four studied groups: $\mathrm{P}<0.05$ was considered significant.

\section{RESULTS}

No mortality was observed throughout the study. The $\mathrm{MnCl} 2$ group showed less active than the other groups. No marked changes in behaviour were observed.

\section{Buried food test}

Manganese chloride group showed a statistically significant increase in time compared to control and propolis groups. $\mathrm{MnCl} 2+$ propolis group showed statistically significant reduction in time compared to $\mathrm{MnCl} 2$ group (Fig. 1).

\section{The area percentage of GFAP immuno-stained}

The area percentage of the GFAP-stained cells in $\mathrm{MnCl} 2$ group was statistically significant increase compared with other studied groups (Table 1).

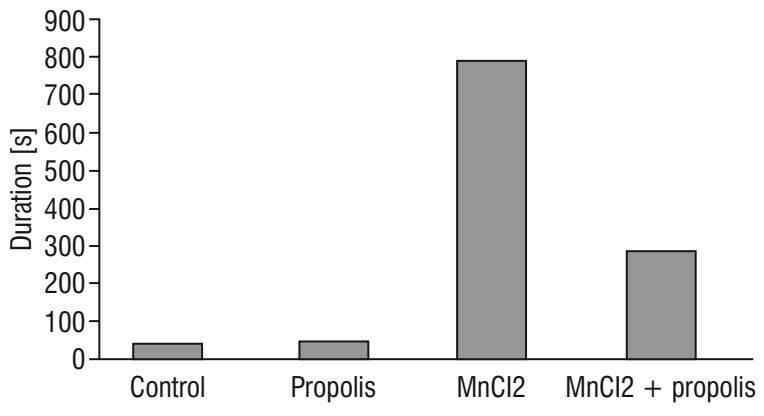

Figure 1. Mean \pm standard deviation duration in seconds of Buried food test; $\mathrm{p}>0.05 ; \mathrm{MnCl} 2$ - manganese chloride.

Table 1. The mean values of area percentage of glial fibrillary acidic protein (GFAP) immunoreaction (mean \pm standard deviation) in different groups ( $p>0.05)$

\begin{tabular}{lc}
\hline & Area percentage of GFAP immunoreaction \\
\hline Control group & $5.949 \pm 0.66$ \\
$\mathrm{MnCl} 2$ group & $11.297 \pm 0.71^{* \#}$ \\
$\mathrm{MnCl} 2+$ propolis group & $6.243 \pm 0.87$ \\
Propolis group & $5.899 \pm 0.64$ \\
\hline
\end{tabular}

*Significant compared to control and propolis group; \#Significant compared to $\mathrm{MnCl} 2$ + propolis group; $\mathrm{MnCl} 2$ - manganese chloride

\section{Histopathological study}

Control and propolis groups. Olfactory bulb sections of control and propolis groups stained by H\&E presented similar heterogeneous architecture and cellular basis, 6 layers appeared from external to internal: olfactory nerve layer contained unmyelinated axons and accumulation of a few organised supporting cells. Glomerular layer showed glomeruli with different size, juxtaglomerular neurons surrounded by typical glomeruli. External plexiform layer consisted of nerve fibres and glial cells. Mitral cell layer showed widely spaced and broken cell bodies of mitral cells arranged in a single row, they had euchromatic nuclei, prominent nucleoli, and Nissl substance in their cell bodies. Internal plexiform layer and granular cell layer. Granular cell layer contains many small granule cells, and Golgi type II cells also noticed (Figs. $2 \mathrm{~A}_{1}, \mathrm{~A}_{2} ; 3 \mathrm{~A}$ ).

Immunohistochemically stained sections of GFAP showed a few positive cells (Fig. 4A, Table 1).

Electron microscopic examination showed normal rounded granule nerve cells with scanty cytoplasm and dark nuclei, mitral nerve cell with euchromatic nuclei and prominent nucleoli. Abundant cytoplasm containing normal rough endoplasmic reticulum 

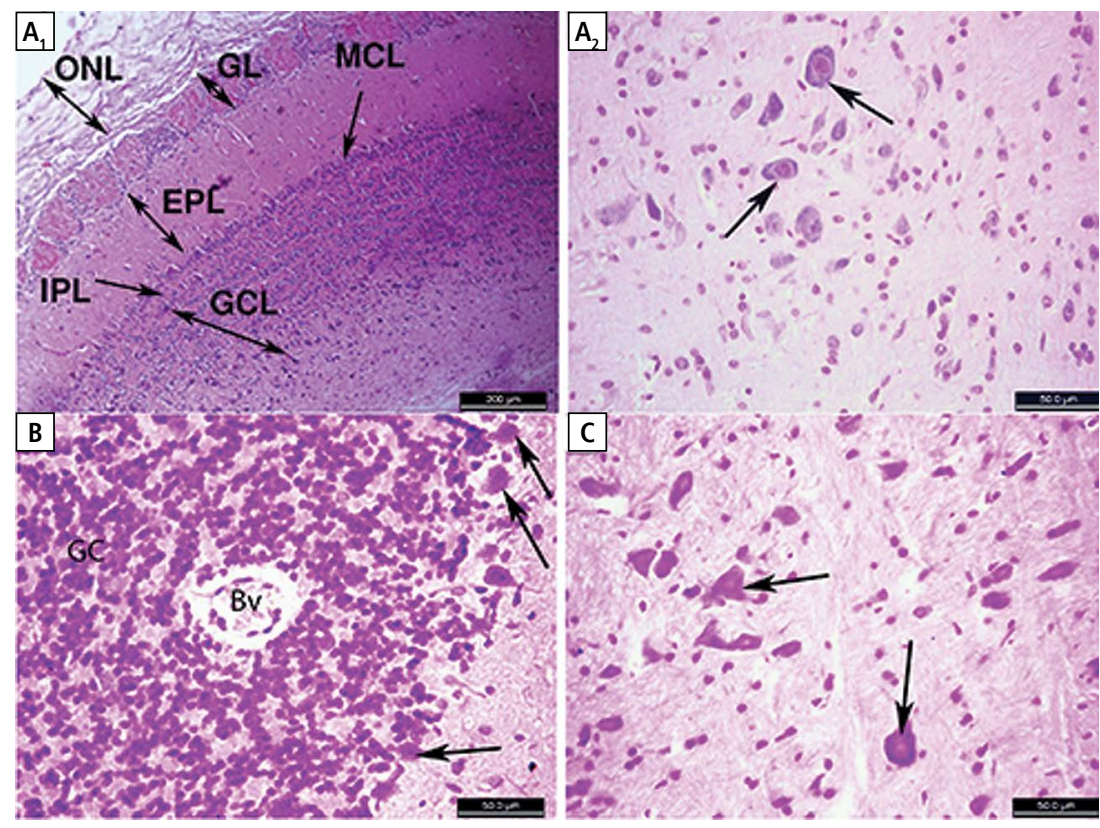

Figure 2. $A_{1}$. A photomicrograph of rat olfactory bulb section control group showing olfactory nerve layer (ONL), glomerular layer (GL), external plexiform layer (EPL), mitral cell layer (MCL), internal plexiform layer (IPL) and granular cell layer (GCL) $\mathbf{A}_{2}$. Mitral cells (arrow) with abundant cytoplasm, euchromatic nuclei, prominent nucleoli and granular cells; B. Manganese chloride ( $\mathrm{MnCl}$ ) group showing darkly stained mitral cells (arrow), dark pyknotic nuclei, congested blood vessel (Bv) and dark apoptotic cells in granular cells (GC); C. $\mathrm{MnCl} 2+$ propolis group showing granular cells and mitral cells (arrow) with abundant cytoplasm.

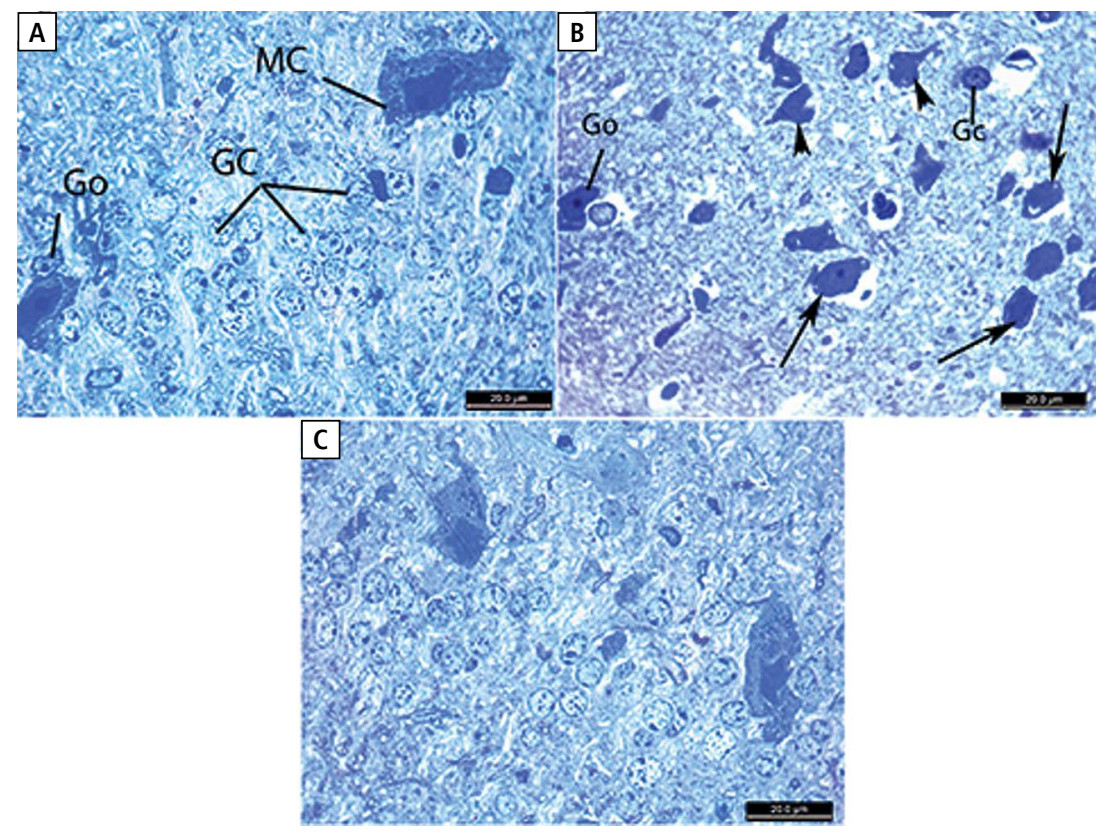

Figure 3. A. A photomicrograph of rat olfactory bulb section control group showing mitral cells $(\mathrm{MC})$ reside in a single row, with abundant cytoplasm contain Nissl substance, euchromatic nuclei and prominent nucleoli, granular nerve cells (GC) with scanty cytoplasm and normal nuclei; Golgi type II cells (Go); B. Manganese chloride $(\mathrm{MnCl} 2)$ group showing darkly stained mitral cells (arrows) with pyknotic nuclei, pericellular spaces and vacuolation. Pyknotic astrocyte (arrowhead), granular cell (Gc) and Golgi type II cell (Go); C. $\mathrm{MnCl} 2$ + propolis group showing normal granular cells and mitral cells with abundant cytoplasm, deeply stained nucleus and normal neuropil.
(RER), mitochondria with normal crista, dense matrix and electron-dense particles most probably free ribosomes were seen (Figs. 5A; 6A, $A_{2}$ ).

Manganese chloride group. Olfactory bulb of $\mathrm{MnCl} 2$ group revealed darkly stained mitral cells with dark pyknotic nuclei; some showed pericellular spaces, vacuolation, congested blood vessels and dark apoptotic cells in granular cells. Neuropil vacuolation, many pyknotic astrocytes, and Golgi type II cells were also present (Figs. 2B; 3B). Immunohistochemically stained sections for GFAP showed a positive reaction in all layers of the olfactory bulb (Fig. 4B, Table 1).

Electron microscopic examination showed abnormal granular cell with irregular damaged nuclear membrane, rupture of myelin fibre. Mitral nerve cell with a destructed nucleus, many cytoplasmic vacuoles, swollen RER, vacuolated mitochondria, neuropil vacuolation and irregular nuclear membrane (Figs. 5B, 6B, $B_{2}$ ).

Manganese chloride + propolis treated group. Normal granular cells arranged in a cluster. Mitral cells appeared with abundant cytoplasm containing 


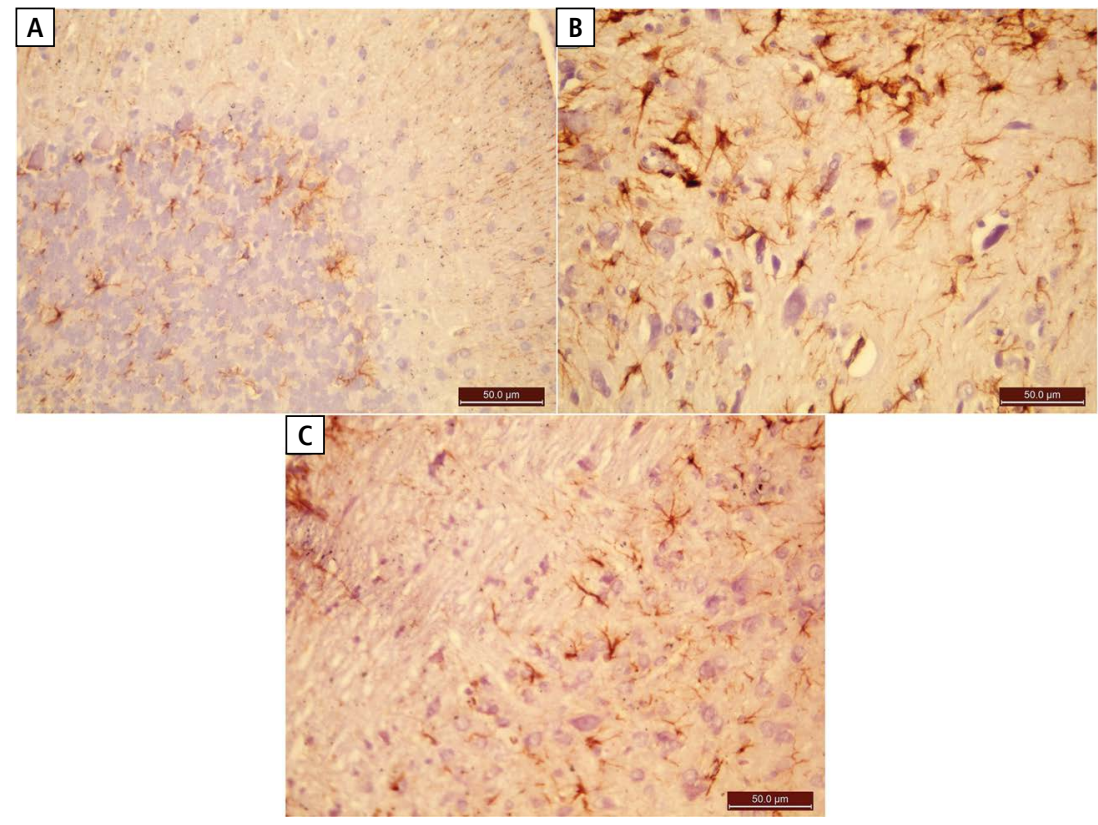

Figure 4. A. A photomicrograph of rat olfactory bulb section control group showing a few positive immunoreaction cells; B. Manganese chloride ( $\mathrm{MnCl}$ ) group showing glial fibrillary acidic protein (GFAP) positive reaction; C. MnCl2 + propolis group showing GFAP positive immuno-reaction.
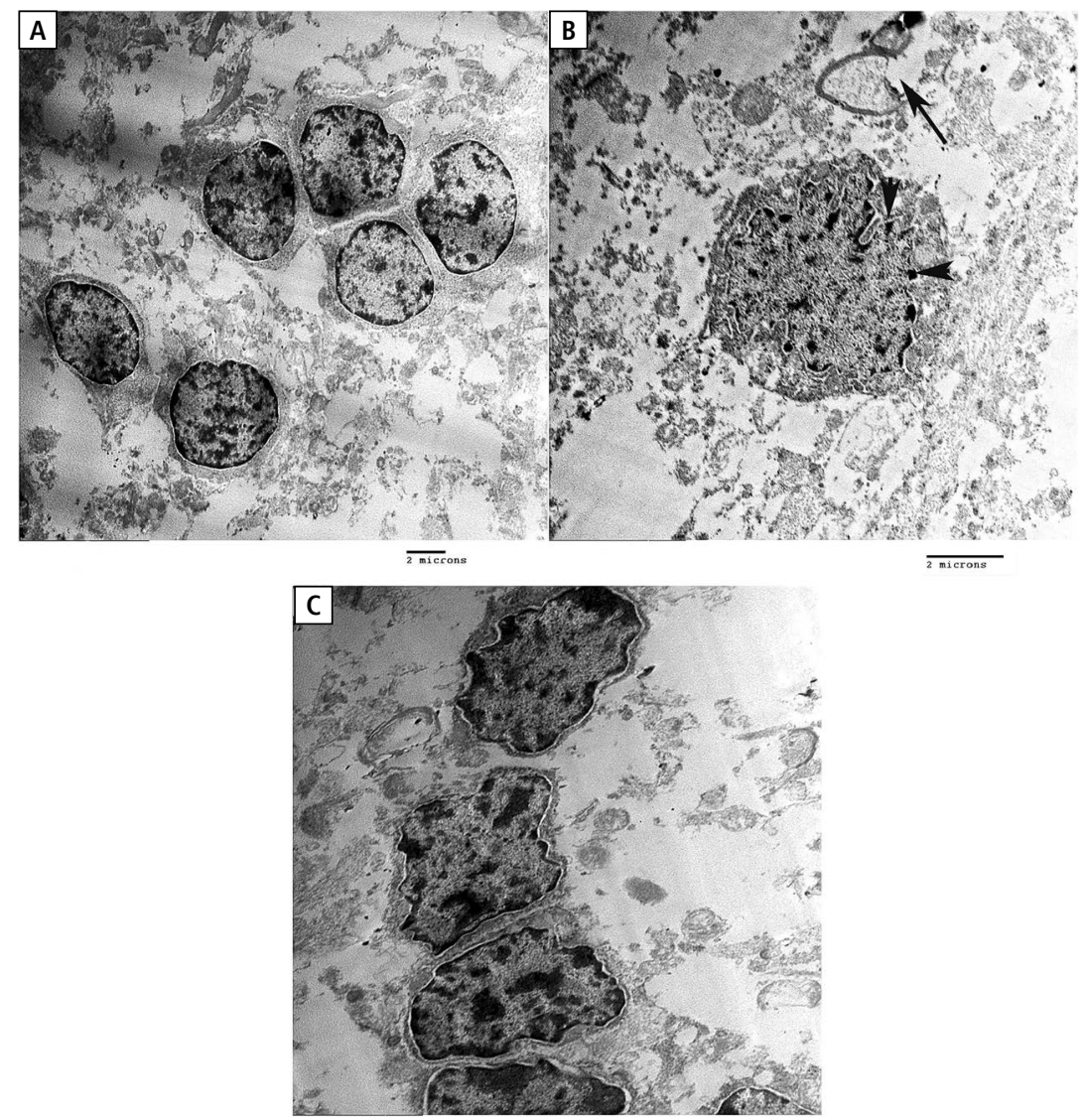

Figure 5. A. An electron micrograph of rat olfactory bulb control group showing normal granular nerve cells with clumped heterochromatin and scanty cytoplasm; B. Manganese chloride (MnCl2) group showing abnormal granular cell with irregular damaged nuclear membrane (arrowhead), rupture of myelin fibre (arrow) and neuropil vacuolation; $\mathbf{C}$. $\mathrm{MnCl} 2+$ propolis group showing cluster of granular cells and vacuolation in neuropil.

Nissl substance in the cell body and deeply stained nucleus. Some cells showed vacuolated cytoplasm and vacuolation of neuropil is still present (Figs. 2C, 3C).
Immunohistochemically stained sections showed GFAP + ve reaction (Fig. 4C, Table 1).

Electron microscopic examination showed a normal cluster of granular cells, vacuolation in neuropil 

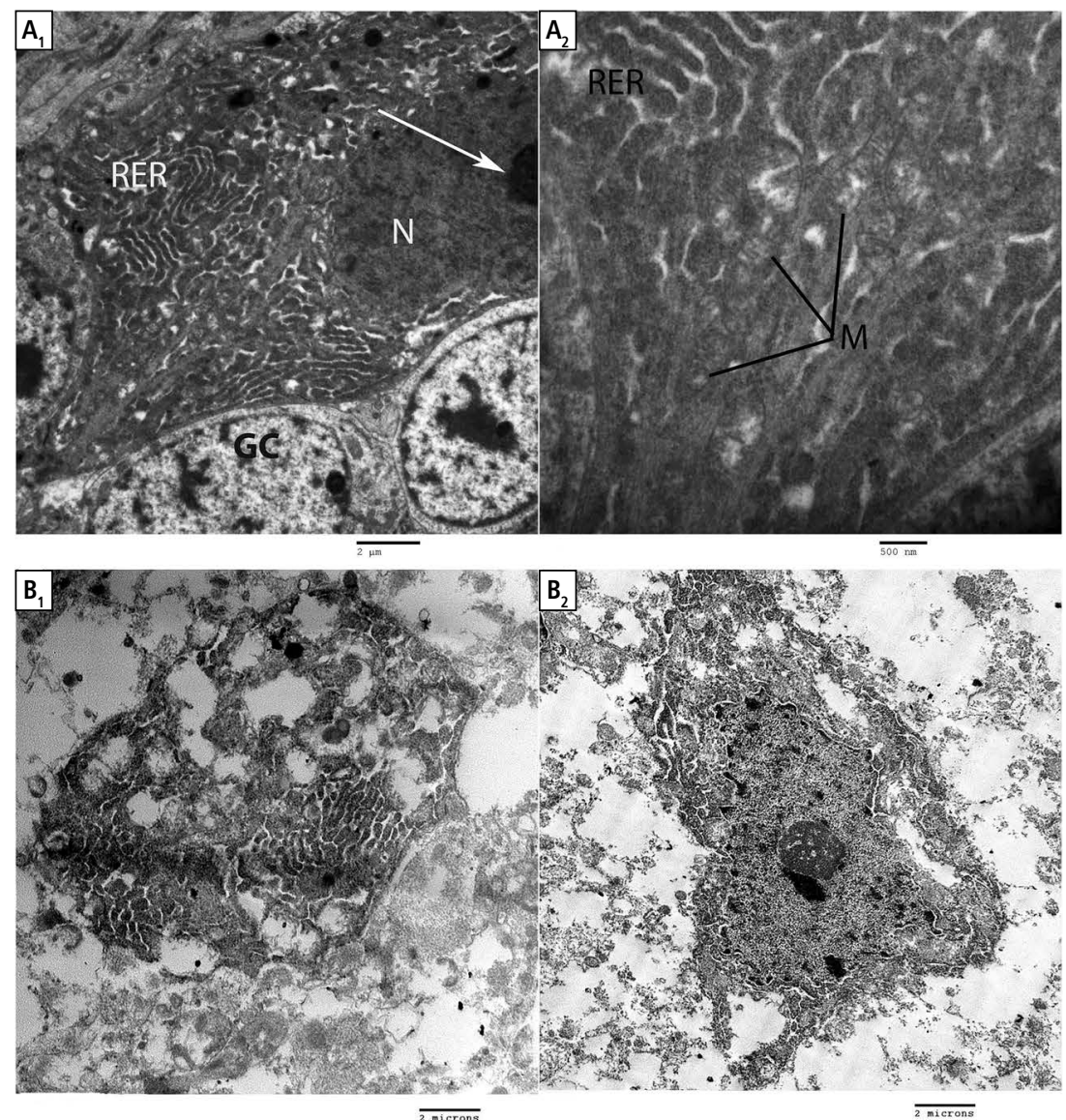

Figure 6. $\mathbf{A}_{1}$. An electron micrograph of rat olfactory bulb control group showing mitral nerve cell with euchromatic nuclei (N) and prominent nucleoli (arrow). Abundant cytoplasm, rough endoplasmic reticulum (RER) and mitochondria. Normal

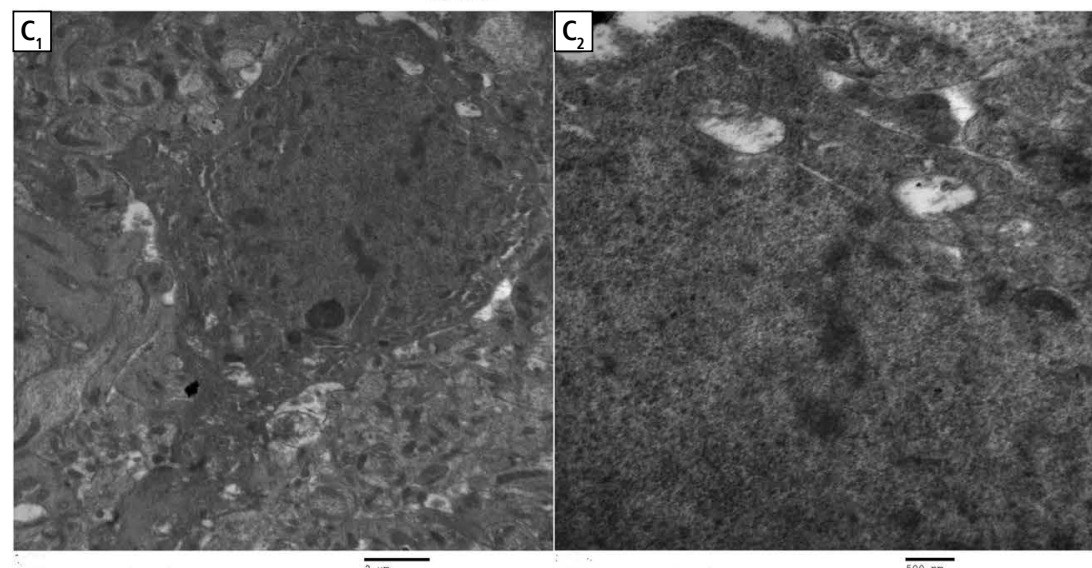
granule cells (GC); $\mathbf{A}_{2}$. Mitochondria (M) with normal crista and dense matrix; B $_{1}$. Manganese chloride $(\mathrm{MnCl} 2)$ group showing mitral cell with destructed nucleus, irregular and damaged nuclear membrane, many cytoplasmic vacuoles, swollen RER and vacuolated mitochondria; $\mathbf{B}_{2}$. Irregular nuclear membrane and neuropil vacuolation with destructed mitochondria; $\mathbf{C}_{1} \cdot \mathrm{MnCl} 2+$ propolis group showing mitral cell with euchromatic nuclei, prominent nucleoli and cytoplasm containing RER, some swollen mitochondria and normal neuropil; $\mathbf{C}_{2}$. Cytoplasm with some slight swollen mitochondria and loss of its cristae.

was still present in some areas. Mitral nerve cells appeared with euchromatic nuclei, prominent nucleoli, cytoplasm containing rough endoplasmic reticulum, some swollen mitochondria with loss of its cristae were still noticed (Figs. 5C; 6C,$C_{2}$ ).

\section{DISCUSSION}

Manganese is a vital nutritional component which plays an appropriate function of numerous biological processes such as blood clotting, bone growth, metabolism, free-radical defence, and production of brain neurotransmitter. $\mathrm{Mn}$ is one of the most used metal worldwide [41]. Pure $\mathrm{Mn}$ is used in the manufacture of dry batteries, glass, and steel industry [20]. Manganese deficiencies infrequently occur in humans; otherwise, its high levels are very destructive to human, independent from exposure route [45].

The current study observed that mitral cells were the most affected cells after exposure to $\mathrm{MnCl} 2$, they showed dark pyknotic nuclei, pericellular vacuolated destructed nucleus, many cytoplasmic vacuoles. Also swollen RER, vacuolated mitochondria, irregular nu- 
clear membrane, congested blood vessels and dark apoptotic cells in the granular cell layer.

Many studies revealed that Mn toxicity is manifesting in central nervous system [11]. High levels of $\mathrm{Mn}$ in the brain lead to a neurotoxic disease (manganism), which resembles idiopathic Parkinson disease (iPD) [23]. Olfaction has been given a lot of value, clinically. Researchers have indicated that olfactory dysfunction in Alzheimer's disease (AD) may precede the clinical emergence of cognitive impairment, and it may be an early sign of brain alteration. Those with olfactory impairment were more likely to develop $A D$ than others [12].

Manganese compound with transferrin will attach to receptors of transferrin in the capillaries of cerebral hemispheres for endocytosis to capillary endothelial cells [18]. Then it is released from systemic transferrin to complex with brain synthesized transferrin to reach the brain tissue. A few amounts of $\mathrm{Mn}$ are bound to citrate, then cross the blood-brain barrier through monocarboxylate transporter [4]. Manganese carriage to brain cells was confirmed to pass through neurons of the olfactory system; its solubility seems to play a major role in transport, with soluble $\mathrm{MnCl} 2$ and $\mathrm{MnSO} 4$ concentration, inhalation of $\mathrm{Mn}$ concentrates mainly in the olfactory bulb [13]. Re-localisation mechanism of $\mathrm{Mn}$ after it reaches the brain had not been fully understood [26]. Mitochondria are the primary target organelles for Mn accumulation, when its concentrations are elevated, $\mathrm{Mn2}+$ is oxidised to $\mathrm{Mn3} 3$, which leads to the production of reactive oxygen species ROS [9]. However, $\mathrm{Mn3}+$ is a potent inhibitor of complex I in the electron transfer chain of mitochondria, which decreases ATP release and increases the outflow of electrons and oxygen radical formation [46]. Mn toxicity may be due to accumulation in mitochondria, causing oxidative stress and dopaminergic neurotoxicity [3]. This finding is consistent with the current study, which showed destruction and vacuolation of mitochondria with absent of its crista.

The beginning of $\mathrm{Mn}$ toxicity was characterised by anxiety, schizophrenia, movement disorders and impaired memory [8]. These findings agreed with the present results as rat in Mn group failed in Buried food test in comparing to other groups.

The current study showed many pyknotic astrocytes in Mn group which is in agreement with other studies that revealed increased accumulation of $\mathrm{Mn}$ in astrocytes. Disorder occurred when extra Mn load on glial cells and astrocytes interrupts their capability of controlling the environment of a neuron. This leads to an increase neurons susceptibility to ROS, excitotoxicity, and toxic product handled by astrocytes [5]. Astrocytes offer neurons with glycine, precursors, and cysteine essential in neuronal glutathione production [14]. Dysfunction of astrocyte delays normal function of the neuron; so, it is reasonable to consider astrocytes as a target of Mn neurotoxicity. Neuronal death is eventually caused by $\mathrm{Mn}$ toxicity, which is initiated directly, or via neuronal/astrocyte disorder. Many hypotheses demonstrate how Mn toxicity leads to neurodegeneration. ROS generation and change in energy metabolism are usually supposed to be reputed mechanisms [21].

Antioxidants are elements that prevent and interrupt oxidation of substrate whereas finding in tiny quantity. Nutritional antioxidants act through different mechanisms as free radical scavengers, decrease peroxide concentrations, repair oxide membranes and reduce ROS release [19]. Th has been shown that antioxidants control the expression of many genes and signal regulatory pathways, and prevent cell death [44].

The present work showed histological improvement in $\mathrm{MnCl} 2+$ propolis treated group.

Propolis is the most antioxidant studied in the research; it has proven to have cardioprotective and neuroprotective effects, and has been suggested as a protective element against AD's [31] and PD's [25]. The basic molecular mechanisms of propolis act as a treatment for cognitive brain function. It significantly inhibits the $\mathrm{H} 2 \mathrm{O} 2$ lead to mitochondria ROS generation and nuclear DNA damage, which induce dysfunction of synaptic efficiency in neuronal cells [31].

Pinocembrin, a flavonoid abundant in propolis, has powerful neuroprotective effects by improving mitochondrial function, inhibiting inflammatory responses, reducing oxidative damage and neuronal apoptosis [28]. Many studies described that, there was a link between oxidative damage, impaired mitochondrial function and increases activities of mitochondrial respiratory complexes II and IV without affecting mitochondrial membrane potential [30]. Recently found that propolis protects against the hypoxia-induced microglia-mediated neuroinflammation [29]. The concomitant administration of propolis with paclitaxel reduced the neurodegenerative changes induced by paclitaxel supported by previous reports where propolis stimulates the neural stem cells differ- 
entiation into neurons and enhances the transcription of the pro-neural genes thus it has an anti-apoptotic effect [2]. Besides, propolis attenuates caspase-3 activities, strengthening the anti-apoptotic effect [40]. Propolis attenuates the diazinon induced nephrotoxicity which confirms its effectiveness as antioxidant and anti-inflammatory [34]. Propolis showed protective effects in spinal cord injury in rabbits exposed to spinal ischemia-reperfusion injury [22]. Propolis protective actions are through a reduction in expression of several inflammatory cytokines in the nucleus and inhibition of oxidative damage to proteins, DNA/RNA, lipids, carbohydrates, and influencing immune responses. So, it is considered a potent neuroprotective agent due to its biological activities based on its flavonoids and infrequent side effects [17]. The possible toxicological effects of propolis extracts were investigated. The results showed that it was quiet safe, no mortalities or signs of toxicity in mice when administered orally at doses up to $5000 \mathrm{mg} / \mathrm{kg}$ body weight [32]. Currently, herbal remedies such as propolis becoming popular because of their beneficial effects with fewer side effects compared to synthetic and semi-synthetic drugs.

\section{CONCLUSIONS}

Manganese chloride lead to toxic effects on rat olfactory bulb, especially of mitral cells which showed destructed nucleus, many cytoplasmic vacuoles, swollen RER and vacuolated mitochondria. $\mathrm{MnCl} 2$ + propolis treated group showed improvement compared to $\mathrm{MnCl} 2$ group. So, it was concluded that propolis can ameliorate the toxic changes of $\mathrm{MnCl} 2$ on rat olfactory bulb.

\section{REFERENCES}

1. Al Badawi $\mathrm{MH}$, Mahmoud $\mathrm{O}$, Salem N. Therapeutic potential of omega-3 against sodium fluoride toxicity on the cerebellar cortex of adult male albino rats. Egyptian J Histol. 2016; 39(2): 170-178, doi: 10.1097/01. ehx.0000490005.17183.4f.

2. Arai MA, Koryudzu K, Koyano T, et al. Naturally occurring Ngn2 promoter activators from Butea superba. Mol Biosyst. 2013; 9(10): 2489-2497, doi: 10.1039/c3mb70083f, indexed in Pubmed: 23903453.

3. Aschner M, Erikson KM, Herrero Hernández E, et al. Manganese and its role in Parkinson's disease: from transport to neuropathology. Neuromolecular Med. 2009; 11(4): 252-266, doi: 10.1007/s12017-009-8083-0, indexed in Pubmed: 19657747.

4. Aschner M, Guilarte TR, Schneider JS, et al. Manganese: recent advances in understanding its transport and neurotoxicity. Toxicol Appl Pharmacol. 2007; 221(2): 131-147, doi: 10.1016/j.taap.2007.03.001, indexed in Pubmed: 17466353.
5. Aschner M, Vrana KE, Zheng W. Manganese uptake and distribution in the central nervous system (CNS). Neurotoxicology. 1999; 20(2-3): 173-180, indexed in Pubmed: 10385881.

6. Bankova V, de Castro SL, Marcucci MC. Propolis: recent advances in chemistry and plant origin. Apidologie. 2000; 31(1): 3-15, doi: 10.1051/apido:2000102.

7. Bowler RM, Nakagawa S, Drezgic M, et al. Sequelae of fume exposure in confined space welding: a neurological and neuropsychological case series. Neurotoxicology. 2007; 28(2): 298-311, doi: 10.1016/j.neuro.2006.11.001, indexed in Pubmed: 17169432.

8. Cersosimo MG, Koller WC. The diagnosis of manganese-induced parkinsonism. Neurotoxicology. 2006; 27(3): 340-346, doi: 10.1016/j.neuro.2005.10.006, indexed in Pubmed: 16325915.

9. Chen CJ, Liao SL. Oxidative stress involves in astrocytic alterations induced by manganese. Exp Neurol. 2002; 175(1): 216-225, doi: 10.1006/exnr.2002.7894, indexed in Pubmed: 12009774.

10. Chen P, Bornhorst J, Aschner M. Manganese metabolism in humans. Front Biosci (Landmark Ed). 2018; 23: 1655-1679, doi: 10.2741/4665, indexed in Pubmed: 29293455.

11. Crossgrove J, Zheng W. Manganese toxicity upon overexposure. NMR Biomed. 2004; 17(8): 544-553, doi: 10.1002/ nbm.931, indexed in Pubmed: 15617053.

12. Devanand DP, Michaels-Marston KS, Liu X, et al. Olfactory deficits in patients with mild cognitive impairment predict Alzheimer's disease at follow-up. Am J Psychiatry. 2000; 157(9): 1399-1405, doi: 10.1176/appi.ajp.157.9.1399, indexed in Pubmed: 10964854.

13. Dorman DC, Brenneman KA, McElveen AM, et al. Olfactory transport: a direct route of delivery of inhaled manganese phosphate to the rat brain. J Toxicol Environ Health A. 2002; 65(20): 1493-1511, doi: 10.1080/00984100290071630, indexed in Pubmed: 12396865.

14. Dringen R. Metabolism and functions of glutathione in brain. Prog Neurobiol. 2000; 62(6): 649-671, doi: 10.1016/ s0301-0082(99)00060-x.

15. El-Masry TA, Emara AM, El-Shitany NA. Possible protective effect of propolis against lead-induced neurotoxicity in animal model. J Evol Biol Res. 2011; 3: 4-11.

16. Ennis M, Hamilton KA, Hayar A. Neurochemistry of the main olfactory system. Handbook of Neurochemistry and Molecular Neurobiology. 2007: 137-204, doi: 10.1007/978-0-387-30374-1_6.

17. Farooqui T, Farooqui AA. Beneficial effects of propolis on human health and neurological diseases. Front Biosci (Elite Ed). 2012; 4: 779-793, doi: 10.2741/418, indexed in Pubmed: 22201913.

18. Fishman JB, Rubin JB, Handrahan JV, et al. Receptor-mediated transcytosis of transferrin across the blood-brain barrier. J Neurosci Res. 1987; 18(2): 299-304, doi: 10.1002/ jnr.490180206, indexed in Pubmed: 3694713.

19. Flora S. Nutritional components modify metal absorption, toxic response and chelation therapy. J Nutr Environ Med. 2009; 12(1): 53-67, doi: 10.1080/13590840220123361.

20. Flynn MR, Susi P. Neurological risks associated with manganese exposure from welding operations--a literature review. Int J Hyg Environ Health. 2009; 212(5): 459-469, doi: 10.1016/j.ijheh.2008.12.003, indexed in Pubmed: 19181573. 
21. Fordahl SC. Effects of manganese exposure and antioxidant therapy on oxidative stress and stereotypic behaviors in rats. The University of North Carolina at Greensboro. 2009.

22. Ilhan A, Koltuksuz U, Ozen S, et al. The effects of caffeic acid phenethyl ester (CAPE) on spinal cord ischemia/reperfusion injury in rabbits. Eur J Cardiothorac Surg. 1999; 16(4): 458-463, doi: 10.1016/s1010-7940(99)00246-8, indexed in Pubmed: 10571095.

23. Iregren A. Manganese neurotoxicity in industrial exposures: proof of effects, critical exposure level, and sensitive tests. Neurotoxicology. 1999; 20(2-3): 315-323, indexed in Pubmed: 10385893.

24. Jaishankar M, Tseten T, Anbalagan N, et al. Toxicity, mechanism and health effects of some heavy metals. Interdiscip Toxicol. 2014; 7(2): 60-72, doi: 10.2478/intox-2014-0009, indexed in Pubmed: 26109881.

25. Jin X, Liu Q, Jia L, et al. Pinocembrin attenuates 6-OHDA-induced neuronal cell death through Nrf2/ARE pathway in SH-SY5Y cells. Cell Mol Neurobiol. 2015; 35(3): 323-333, doi: 10.1007/s10571-014-0128-8, indexed in Pubmed: 25377066.

26. Leavens TL, Rao D, Andersen ME, et al. Evaluating transport of manganese from olfactory mucosa to striatum by pharmacokinetic modeling. Toxicol Sci. 2007; 97(2): 265-278, doi: 10.1093/toxsci/kfm061, indexed in Pubmed: 17372280.

27. Lehmkuhl AM, Dirr ER, Fleming SM. Olfactory assays for mouse models of neurodegenerative disease. J Vis Exp. 2014(90): e51804, doi: 10.3791/51804, indexed in Pubmed: 25177842.

28. Liu $\mathrm{R}, \mathrm{Wu} C X$, Zhou $\mathrm{D}$, et al. Pinocembrin protects against $\beta$-amyloid-induced toxicity in neurons through inhibiting receptor for advanced glycation end products (RAGE)-independent signaling pathways and regulating mitochondrion-mediated apoptosis. BMC Med. 2012; 10: 105, doi: 10.1186/1741-7015-10-105, indexed in Pubmed: 22989295.

29. Liu Y, Wu Z, Zhang X, et al. Leptomeningeal cells transduce peripheral macrophages inflammatory signal to microglia in reponse to Porphyromonas gingivalis LPS. Mediators Inflamm. 2013; 2013: 407562, doi: 10.1155/2013/407562, indexed in Pubmed: 24363500.

30. Maier CM, Chan PH. Role of superoxide dismutases in oxidative damage and neurodegenerative disorders. Neuroscientist. 2002; 8(4): 323-334, doi: 10.1177/107385840200800408, indexed in Pubmed: 12194501.

31. Ni J, Wu Z, Meng J, et al. The neuroprotective effects of brazilian green propolis on neurodegenerative damage in human neuronal SH-SY5Y cells. Oxid Med Cell Longev. 2017; 2017: 7984327, doi: 10.1155/2017/7984327, indexed in Pubmed: 28265338.

32. Ramadan A, Soliman G, Mahmoud S, et al. Evaluation of the safety and antioxidant activities of Crocus sativus and Propolis ethanolic extracts. J Saudi Chem Soc. 2012; 16(1): 13-21, doi: 10.1016/j.jscs.2010.10.012.

33. Ramos-Vara JA, Kiupel M, Baszler T, et al. Suggested guidelines for immunohistochemical techniques in veterinary diagnostic laboratories. J Vet Diagn Invest. 2008; 20(4):
393-413, doi: 10.1177/104063870802000401, indexed in Pubmed: 18599844.

34. Salem NA, Al Ba, Hussein HH. Protective role of propolis on diazinon induced nephrotoxicity in adult male albino rats. Eur J Anat. 2015; 19: 331-342.

35. Santos AP, Lucas RL, Andrade $V$, et al. Protective effects of ebselen (Ebs) and para-aminosalicylic acid (PAS) against manganese $(\mathrm{Mn})$-induced neurotoxicity. Toxicol Appl Pharmacol. 2012; 258(3): 394-402, doi: 10.1016/j. taap.2011.12.003, indexed in Pubmed: 22178737.

36. Schneider CA, Rasband WS, Eliceiri KW. NIH Image to ImageJ: 25 years of image analysis. Nat Methods. 2012; 9(7): 671-675, doi: 10.1038/nmeth.2089, indexed in Pubmed: 22930834.

37. Seven I, Aksu T, Seven P. The Effects of propolis on biochemical parameters and activity of antioxidant enzymes in broilers exposed to lead-induced oxidative stress. Asian-Australasian J Animal Scien. 2010; 23(11): 1482-1489, doi: 10.5713/ajas.2010.10009.

38. Sforcin JM. Propolis and the immune system: a review. J Ethnopharmacol. 2007; 113(1): 1-14, doi: 10.1016/j. jep.2007.05.012, indexed in Pubmed: 17580109.

39. Stallings WC, Metzger AL, Pattridge KA, et al. Structure-function relationships in iron and manganese superoxide dismutases. Free Radic Res Commun. 1991; 12-13 Pt 1: 259-268, doi: 10.3109/10715769109145794, indexed in Pubmed: 2071033.

40. Swamy M, Suhaili D, Sirajudeen KNS, et al. Propolis ameliorates tumor nerosis factor- $\alpha$, nitric oxide levels, caspase- 3 and nitric oxide synthase activities in kainic acid mediated excitotoxicity in rat brain. Afr J Tradit Complement Altern Med. 2014; 11(5): 48-53, doi: 10.4314/ajtcam.v11i5.8, indexed in Pubmed: 25395704.

41. Takeda A. Manganese action in brain function. Brain Res Brain Res Rev. 2003; 41(1): 79-87, doi: 10.1016/s01650173(02)00234-5, indexed in Pubmed: 12505649.

42. Thompson KJ, Molina RM, Donaghey T, et al. Manganese uptake and distribution in the brain after methyl bromide-induced lesions in the olfactory epithelia. Toxicol Sci. 2011; 120(1): 163-172, doi: 10.1093/toxsci/kfq387, indexed in Pubmed: 21177252.

43. Yang Mu, Crawley JN. Simple behavioral assessment of mouse olfaction. Curr Protoc Neurosci. 2009; Chapter 8: Unit 8.24, doi: 10.1002/0471142301.ns0824s48, indexed in Pubmed: 19575474.

44. Young IS, Woodside JV. Antioxidants in health and disease. J Clin Pathol. 2001; 54(3): 176-186, doi: 10.1136/ jcp.54.3.176, indexed in Pubmed: 11253127.

45. Zaiyang L, Yue-Ming J, Xiang-Rong Li, et al. Vulnerability of welders to manganese exposure: a neuroimaging study. NeuroToxicology. 2014; 45: 285-292, doi: 10.1016/j. neuro.2014.03.007.

46. Zhang S, Fu J, Zhou Z. In vitro effect of manganese chloride exposure on reactive oxygen species generation and respiratory chain complexes activities of mitochondria isolated from rat brain. Toxicol In Vitro. 2004; 18(1): 71-77, doi: 10.1016/j.tiv.2003.09.002, indexed in Pubmed: 14630064 